\title{
PROPOSTA DE UM PLANO DE RECUPERAÇÃO DE ÁREA DEGRADADA POR ATIVIDADE DE MINERAÇÃO
}

\section{PROPOSAL FOR A DEGRADED AREA RECOVERY PLAN OF MINING ACTIVITY}

\author{
Luciana Nogueira Lavina \\ Universidade Federal de Santa Catarina \\ Gustavo Aveiro Lins \\ CEDERJ/SEE-RJ/CEDAE \\ Everton Costa \\ Universidade do Estado do Rio de Janeiro \\ Diana Carvalho Rocha \\ Universidade Gama Filho \\ Elenice Rachid \\ Programa de Engenharia de Transportes da Coppe/UFRJ \\ Josimar Ribeiro de Almeida \\ Universidade do Estado do Rio de Janeiro - UERJ \\ Universidade de São Paulo - USP
}

\section{RESUMO}

Uma série de instrumentos legais, a começar pela Constituição Federal, regula as atividades potencialmente poluidoras, ditando normas e procedimentos para que as operações transcorram dentro de condições de controle. O artigo 225 da Constituição, também conhecido como Capítulo do Meio Ambiente, estabelece que "Todos têm direito ao meio ambiente ecologicamente equilibrado, bem de uso comum do povo e essencial à sadia qualidade de vida, impondo-se ao poder público e à coletividade o dever de defendê-la e preservá-la para as presentes e futuras gerações". Este artigo incumbe ao poder público "exigir, na forma da lei, para instalação de obra ou atividade potencialmente degradadora do meio ambiente, estudo prévio de impacto ambiental, a que se dará publicidade". Determinase, ainda, que "aquele que explorar recursos minerais fica obrigado a recuperar o meio ambiente degradado, de acordo com solução técnica exigida pelo órgão público competente, na forma da lei". A recuperação de áreas degradadas pela mineração normalmente envolve atividades que têm o objetivo de restabelecer a vegetação. A degradação dos solos constituise um prejuízo socioeconômico e representa um enorme risco para as gerações futuras, pois estas áreas perdem a vegetação, ficando com solos descobertos e empobrecidos, sofrendo erosões, como também ocorrem instabilidades hidrológicas, perda da matéria orgânica, 
minerais e da diversidade biológica. É necessário que tais áreas sejam recuperadas, objetivando restabelecer o equilíbrio.

Palavras-Chaves: Recuperação ambiental; Áreas degradadas; Mineração, Replantio.

\begin{abstract}
A series of legal instruments, starting with the Federal Constitution, regulate the activities of potential polluters, by dictating norms and procedures for those operations that should occur under controlled conditions. Article 225 of the Constitution, known as the Chapter on the Environment, establishes that, "All shall have the right to a balanced ecological environment, with proper use of public access areas being essential to health and quality of life, empowering the public and the collective the duty to defend and preserve it for future generations." This Article requires that the government provide, according to law, environmental impact studies to the public prior to execution of work or potentially degrading activities to the environment. Further, it is indicated that, by law, the activities for the exploitation of mineral resources be required to recuperate the impact to the affected environmental conditions, according to a technical solution provided by a competent public organ. The recuperation of regions impacted by mining operations normally involve activities of with the objective to reestablish the vegetation. The degradation of the soil constitute a socioeconomic threat and represent an enormous risk to future generations because these areas lose the vegetation leaving the soils uncovered and undernourished, suffer erosion and potential drainage instabilities. Therefore, it is important that the affected areas be reestablished to its natural balance and equilibrium.
\end{abstract}

Key words: Ambient recovery, Degraded areas, Mining, Replantation.

\title{
INTRODUÇÃO
}

A estabilidade dos ecossistemas está mais do que nunca ameaçada devido ao impacto do desenvolvimento tecnológico sem precedentes. Esta exploração não planejada de recursos naturais acarreta modificações intensas ou irreversíveis. Tal quadro torna-se ainda mais preocupante porque os países onde existem as maiores concentrações de recursos orgânicos diversificados são aqueles que mais precisam incrementar a sua qualidade de vida e normalmente, desenvolvimento implica em utilização de recursos naturais.

Uma série de medidas legais foram tomadas nos últimos tempos com o objetivo de garantir a preservação, melhoria e recuperação dos recursos naturais, e sobre tudo visando assegurar o desenvolvimento socioeconômico. Entre elas, o sistema de licenciamento ambiental conferido pela Lei 6.938 de 08/81 e regulamentado pelo Decreto 99.274 de 06/90, no qual o órgão competente licencia 
a localização, instalação e ampliação de atividades e empreendimentos, potencialmente causadores de degradações ambientais.

O PRAD foi regulamentado pelo Decreto Federal n‥ 97.632/89, que dispôs em seu artigo $1^{\circ}$ que os empreendimentos destinados à exploração de recursos minerais deveriam, quando da apresentação do Estudo de Impacto Ambiental - EIA e do Relatório de Impacto Ambiental - RIMA, submeter à aprovação do órgão ambiental competente um plano de recuperação de área degradada.

Tal se fez porquanto, conforme é sabido, a atividade minerária extrativa sempre foi, em sua maioria, realizada sem técnicas adequadas e sem controle efetivo, gerando por consequência quadro de degradação gravíssimo na área que a abriga.

Com efeito, o processo de extração e de deposição de rejeitos decorrentes da atividade de mineração como o caso da propriedade objeto deste trabalho, causa alterações de grande impacto no terreno, já que o produto mineral extraído nunca mais retorna ao local da extração, permanecendo em circulação, servindo unicamente ao homem e às suas necessidades. $O$ presente trabalho tem como objetivo propor um plano de revegetação da área degradada pelo processo de extração mineral, tendo como modelo uma jazida localizada no km 33-400 LD da rodovia SC-440, constituindo uma medida de recuperação do ecossistema perturbado.

\section{MATERIAIS E MÉTODOS}

\section{Localização da propriedade}

A propriedade objeto do presente trabalho possui $4.800 \mathrm{~m}^{2}$ e está situada na localidade denominada Guarda margem direita, município de Tubarão, Santa Catarina, no km 63 da Rodovia SC 440. A propriedade está em nome de Edgar Fraga de Oliveira sob matrícula 6.512 no registro $4 / 6.512$ pg. 13 do livro de Registro Geral $n^{\circ} 2$ AC. O acesso se dá através da SC 440, percorrendo cerca de $9 \mathrm{~km}$ a partir do município de Tubarão. A área localiza-se entre as latitudes $28^{\circ} 26^{\prime} 98^{\prime}$ e longitudes 4905'36" a altitude média é 68 metros. 


\section{Origem da degradação}

A degradação da área objeto do presente trabalho se dará por conta da atividade de extração mineral, causando a supressão da vegetação (em maior parte exótica, Eucaliptus sp.) além da movimentação e remoção de grandes volumes de terras. Esse fato certamente ocasionará o aumento dos processos erosivos alterando a sedimentação dos corpos d'água; o empobrecimento do solo; e principalmente no aspecto paisagístico de modo geral.

Todos esses danos ocorrerão de maneira mais intensa na fase de operação do empreendimento, sendo os efeitos de longo a médio prazo e a reversibilidade de forma parcial. Caso não haja um projeto de recuperação da área, logo que possível, os efeitos dos danos poderão se estender por um longo tempo dificultando a resiliência do ambiente alterado.

\section{Preparo do Solo}

O preparo do solo visa melhorar as condições físicas do solo e/ou incorporar fertilizantes e corretivos, para favorecer o estabelecimento do povoamento.

As técnicas e equipamentos a serem utilizados no preparo do solo irão depender das características físicas, químicas e topográficas do solo, bem como da disponibilidade de recursos financeiros para a execução do mesmo. Assim antes de tudo a primeira medida a ser tomada será a devida coleta e análise do solo na área do PRAD.

De modo geral, a correção do $\mathrm{pH}$ do solo deverá ser feita mediante calagem conforme análise de solo, mantendo seu valor por volta de 6,0 a 6,5 por ser a faixa ideal para o desenvolvimento da maioria das plantas. Quanto à fertilização, nas covas, deverá ser de forma a corrigir deficiências mais severas dos principais nutrientes, utilizando preferencialmente adubação orgânica.

Sugere-se que $O$ aproveitamento do material orgânico superficial não utilizado, para a mineração (horizonte A) seja utilizado na recomposição e reestruturação do solo. 


\section{Método de regeneração}

Vários critérios devem ser levados em conta na seleção da metodologia de regeneração a ser empregada em uma determinada área, dentre eles os objetivos finais, as características físico-biológicas da área, a eficiência do método, sobretudo o custo de implantação.

\section{Regeneração Artificial}

Tendo como base os aspectos acima citados, o método selecionado para a implantação do projeto será a Revegetação Artificial, que além de acelerar o processo natural de regeneração, esse método oferece vantagens sobre o controle da densidade e espaçamento do povoamento, além da possibilidade de introdução de material geneticamente superior. Como desvantagens prevalecem as questões de custo e mão-de-obra.

Para a revegetação deverá ser utilizado o plantio de mudas de espécies nativas. Esse é o método mais comumente empregado no Brasil para reflorestamentos, entretanto a problemática está associada tanto à dificuldade de obtenção de diversidade de espécies, quanto na quantidade de mudas destas (Alvarenga, 2004).

\section{Operações técnicas}

Espaçamento: nesta situação onde já existe uma cobertura dominada por gramíneas e outras invasoras, será utilizado um modelo de alta densidade de pioneiras agressivas e sombreadoras para recobrir rapidamente o solo, assim como controlar as invasoras. O espaçamento mais indicado é de $2 \times 3 \mathrm{~m}$, sendo a densidade de 1.666 mudas florestais/ha. Neste caso, pode-se plantar no primeiro ano as pioneiras e no segundo as não pioneiras;

Combate às Formigas: a área de plantio deverá ser percorrida na sua totalidade para a localização de formigueiros. Necessitando combatê-los, a utilização de formicidas deverá ficar sob orientação do engenheiro agrônomo 
responsável pela execução;

Alinhamento para Marcação das Covas e Distribuição das Espécies: consiste na determinação dos pontos onde deverão ser abertas as covas, sendo que as linhas de plantio devem ser alinhadas paralelamente às curvas de nível, seguindo o sistema (tabela 1). Este modelo consiste na implantação de uma linha de pioneiras alternada com uma linha de não pioneiras. O plantio poderá ser simultâneo ou em épocas diferentes. A distribuição das plantas nas linhas pode ser ao acaso, misturando-as antes do plantio, ou numa forma sistemática, colocando as espécies disponíveis numa sequência estabelecida. A principal vantagem deste método está na facilidade de implantação. Como desvantagem, se for utilizado o plantio simultâneo, as plantas das não pioneiras levarão mais tempo para receber sombreamento, o que retardará seu desenvolvimento;

Coroamento: deverá ser feito ao redor das covas para evitar a competição das ervas daninhas, com raio de 0,60 metros;

Coveamento: consiste na abertura das covas previamente marcadas, que deverão obedecer às dimensões de 0,30 x 0,30 x 0,40 m;

Adubação das covas: devido ao fato de não existir recomendação de adubação para espécies florestais nativas, sugere-se a adição por cova, de 20 I de esterco de curral curtido. Os adubos deverão sofrer uma mistura homogênea com o volume da terra retirada da cova;

Plantio das mudas: embora se trate de uma operação simples, alguns cuidados deverão ser tomados. A embalagem da muda deverá ser retirada totalmente, tomando-se o cuidado para não desmanchar o torrão. Se a raiz principal tiver sua extremidade torcida, essa porção deverá ser podada, bem como duas raízes laterais. A seguir deverá ser colocada na cova sobre uma pequena porção da mistura de terra adubada, completando-se os espaços ao seu redor com o restante da mistura, que deverá ser compactada adequadamente. $O$ colo da muda deverá ficar em concordância com o nível do terreno, recoberto por uma leve camada de terra. Todo o restante da terra após o plantio será disposto em coroa ao redor da muda, com um raio mínimo de 0,20 m, assegurando-se assim um melhor armazenamento de água das chuvas;

Irrigação: Os plantios deverão ser realizados preferencialmente em dias chuvosos. Caso não seja possível, deverá ser providenciada a irrigação das covas e sulcos imediatamente após o plantio. As covas e sulcos deverão receber uma 
quantidade de água suficiente até o completo encharcamento do solo;

Isolamento: o isolamento da área, impedindo o acesso de animais (gado) é fator primordial para o estabelecimento das espécies e a garantia do sucesso do projeto;

Cobertura verde: recomenda-se que juntamente com a implantação das mudas nativas seja feito a implantação de cobertura verde para melhorar a estrutura e fertilidade do solo e diminuindo os processos erosivos, escoamento superficial e aumentando a infiltração.

Figura 1. Esquema de disposição das espécies, adaptado do modelo proposto por Macedo (1993).
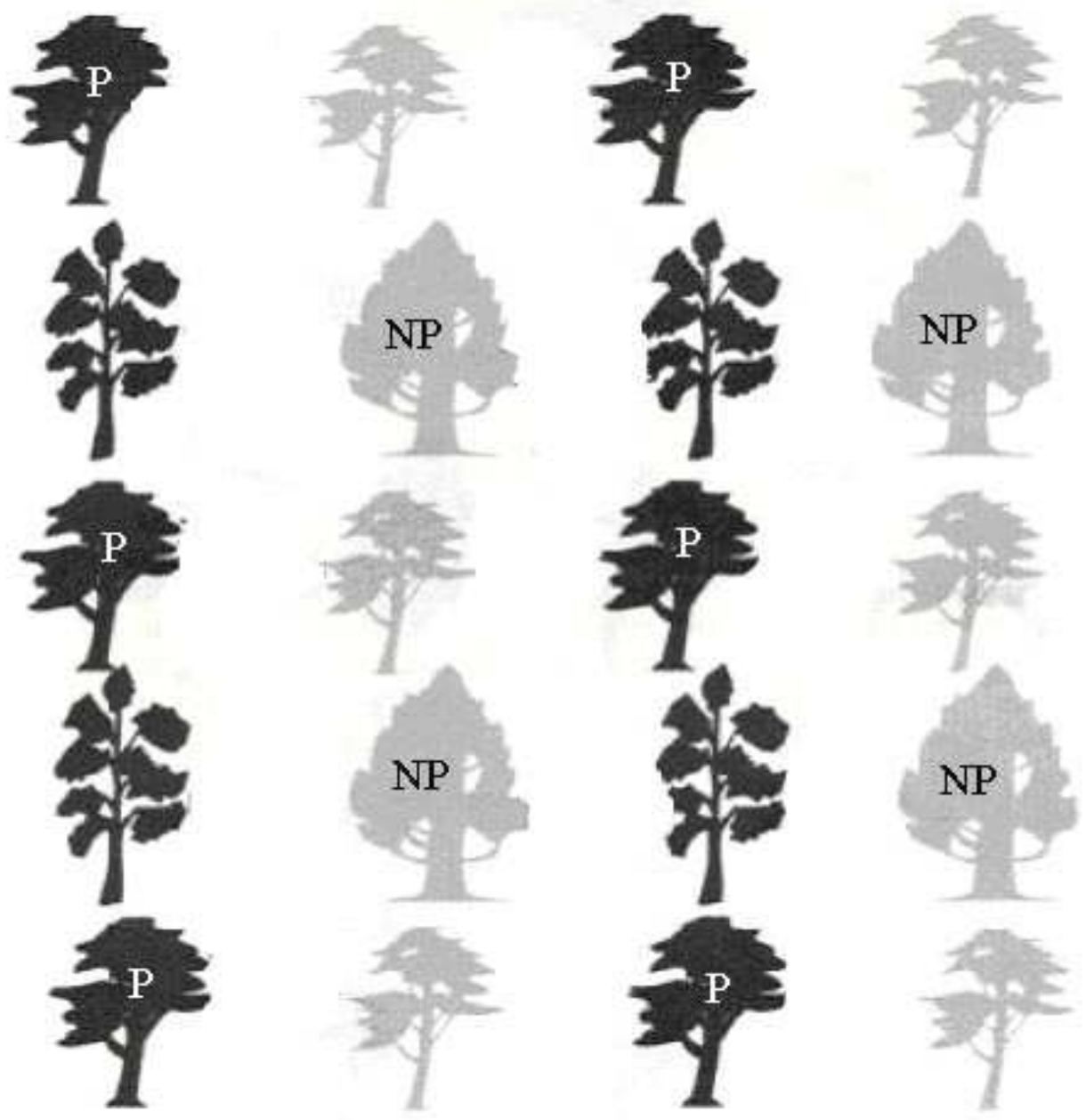


\section{RESULTADOS E DISCUSSÃO \\ Metodologia dos tratos culturais e intervenções}

Após o plantio será iniciado o programa de manutenção, que consiste em atividades complementares visando o sucesso do programa de recuperação. De modo esta etapa resume-se em:

- Reposição das mudas que deverá ser realizado 30 dias após o plantio, caso seja constatada a "morte" da muda, devendo ser utilizado os mesmos moldes estabelecidos no modelo proposto;

- Capinamento ou limpeza das plantas herbáceas, principalmente das gramíneas invasoras que crescem nas entrelinhas de plantio. Se possível (dependendo da agressividade das plantas invasoras) proceder somente com o coroamento ao redor da muda, em um raio correspondente à projeção da copa;

- Programa de fertilização periódica, observando nas plantas, possíveis sintomas manifestados pela ausência de nutrientes. A fertilização se dará por meio de adubação orgânica e biofertilizantes (supermagro) evitando assim a contaminação dos corpos d'água;

- Controle de pragas e doenças, caso seja necessário, procurando utilizar técnicas de tratamento orgânico (como uso de caldas bordalesa, sulfocálcica);

- O controle de formigas que deverá ser feito caso haja necessidade, através de armadilhas (Bórax com açúcar);

- A irrigação de manutenção deverá ser realizada quando, por condições adversas, as mudas aproximarem do ponto de murcha permanente;

- Outras atividades são: desbaste, aceiramento, podas, condução, etc. 


\section{Metodologia de avaliação da recuperação/monitoramento}

Nesta etapa serão desenvolvidos conjuntos de ações e procedimentos destinados para avaliar o sucesso ou avanço da recuperação da área. O principal objetivo é verificar se as metas delineadas estão sendo atingidas e se existem aspectos que devam ser reavaliados ou ajustados para desta forma obter um diagnóstico sobre o processo de recuperação.

\section{Indicadores de avaliação da implantação vegetal}

O primeiro indicador que será utilizado se refere à porcentagem de mortalidade e sobrevivência de mudas. O procedimento consiste apenas, na contagem das mudas mortas em relação àquelas sobreviventes. Esse indicador fornecerá uma estimativa relativa do sucesso da implantação, auxiliando na decisão sobre a necessidade de replantio.

\section{Indicadores de avaliação de pós-implantação}

Para as fases de pós-implantação a avaliação da revegetação irá considerar os seguintes aspectos:

a) Desenvolvimento das mudas (início 30 dias após o plantio);

- $\quad$ Estado nutricional e fitossanitário;

- Desenvolvimento e crescimento das mudas em uma escala cronológica determinada (ex. anual);

- Diâmetro na base do caule, que expressará a área basal da comunidade;

- $\quad$ Altura total e do fuste, que permitirá uma avaliação do volume da vegetação e consequentemente da biomassa, através da utilização de paquímetro. 
Os indicadores apresentados serão considerados individualmente por espécies tendo em vista o desenvolvimento diferenciado.

b) Levantamento fitossociológico

Para o estudo da composição, dinâmica, estrutura e regeneração serão instaladas após o primeiro semestre da implantação, 4 parcelas permanentes de 10 x 10 m demarcadas com estacas e distribuídas aleatoriamente dentro da área minerada. Serão utilizados os parâmetros básicos de avaliação como: frequência absoluta e relativa, dominância absoluta e relativa, índice de diversidade e regeneração natural.

c) Levantamento florístico da regeneração natural

Será demarcada uma sub-parcelas de $5 \times 5 \mathrm{~m}$ dentro das parcelas do levantamento fitossociológico, para avaliar a instalação de plântulas no sub-bosque, considerando todos os indivíduos com DAP inferior a $5 \mathrm{~cm}$ e altura maior que 10 $\mathrm{cm}$. Esses indivíduos serão identificados por espécies, família botânica, nome popular, calculando a frequência e dominância dentro de cada parcela. O cronograma de execução está descrito na tabela 2. 
Tabela 1. Cronograma de Físico de Execução, Tratos Culturais e Avaliação

\section{CRONOGRAMA DE EXECUÇÃO/TRATOS CULTURAIS/AVALIAÇÃO}

\begin{tabular}{|c|c|c|c|c|c|c|c|c|c|c|c|c|c|c|c|c|}
\hline \multirow{2}{*}{ Operações (trimestre) } & \multicolumn{2}{|r|}{1} & \multicolumn{2}{|c|}{ ANO } & \multicolumn{2}{|r|}{2} & \multicolumn{2}{|c|}{ ANO } & \multicolumn{2}{|r|}{3} & \multicolumn{2}{|c|}{ ANO } & \multicolumn{2}{|r|}{4} & \multicolumn{2}{|c|}{ ANO } \\
\hline & 1 & 2 & 3 & 4 & 1 & 2 & 3 & 4 & 1 & 2 & 3 & 4 & 1 & 2 & 3 & 4 \\
\hline \multicolumn{17}{|l|}{ PREPARO DO SOLO } \\
\hline Análise & $\mathbf{x}$ & & & & & & & & & & & & & & & \\
\hline Correção & & $\mathbf{x}$ & & & & & & & & & & & & & & \\
\hline \multicolumn{17}{|l|}{ IMPLANTAÇÃO } \\
\hline Combate a formigas & $\mathbf{x}$ & & & & & & & & & & & & & & & \\
\hline Alinhamento & & $\mathbf{x}$ & & & & & & & & & & & & & & \\
\hline Coveamento & & $\mathbf{x}$ & & & & & & & & & & & & & & \\
\hline Adubação & & $\mathbf{x}$ & & & & & & & & & & & & & & \\
\hline Plantio & & $\mathbf{x}$ & & & & & & & & & & & & & & \\
\hline Coroamento & & $\mathbf{x}$ & & & & & & & & & & & & & & \\
\hline Irrigação & & $\mathbf{x}$ & & & & & & & & & & & & & & \\
\hline Isolamento da área & & $\mathbf{x}$ & & & & & & & & & & & & & & \\
\hline \multicolumn{17}{|l|}{ MANUTENÇÃO } \\
\hline Reposição de mudas & $\mathbf{x}$ & $\mathbf{x}$ & & $\mathbf{x}$ & & & & & & & & & & & & \\
\hline Capina & & $\mathbf{x}$ & & & $\mathbf{x}$ & & & $\mathbf{x}$ & & & $\mathbf{x}$ & & & $\mathbf{x}$ & & \\
\hline Fertilização & & $\mathbf{x}$ & & & & $\mathbf{x}$ & & & & $\mathbf{x}$ & & & & $\mathbf{x}$ & & \\
\hline Controle de pragas & & $\mathbf{x}$ & & & $\mathbf{x}$ & & & $\mathbf{x}$ & & & $\mathbf{x}$ & & & $\mathbf{x}$ & & \\
\hline Controle de doenças & & $\mathbf{x}$ & & & $\mathbf{x}$ & & & $\mathbf{x}$ & & & $\mathbf{x}$ & & & $\mathbf{x}$ & & \\
\hline Controle de formigas & & $\mathbf{x}$ & & $\mathbf{x}$ & & & $\mathbf{x}$ & & & $\mathbf{x}$ & & & $\mathbf{x}$ & & & $\mathbf{x}$ \\
\hline Desbastes e podas & & & $\mathbf{x}$ & & $\mathbf{x}$ & & & $\mathbf{x}$ & & & $\mathbf{x}$ & & & $\mathbf{x}$ & & \\
\hline MONITORAMENTO & & & $\mathbf{x}$ & & & & & & & & & & & & & \\
\hline \multicolumn{17}{|l|}{ Demarcação das parcelas } \\
\hline Avaliação dos padrões fitossociológicos & & & & $\mathbf{x}$ & & & & $\mathbf{x}$ & & & & $\mathbf{x}$ & & & & $\mathbf{x}$ \\
\hline Tabulação dos dados & & & & $\mathbf{x}$ & & & & $\mathbf{x}$ & & & & $\mathbf{x}$ & & & & $x$ \\
\hline Elaboração de relatório & & & & $\mathbf{x}$ & & & & $\mathbf{x}$ & & & & $\mathbf{x}$ & & & & $\mathbf{x}$ \\
\hline Entrega do relatório & & & & $\mathbf{x}$ & & & & $\mathbf{x}$ & & & & $\mathbf{x}$ & & & & $\underline{\mathbf{x}}$ \\
\hline
\end{tabular}




\section{CONCLUSÕES}

Nas atividades de extração não é exagero afirmar que as questões ambientais ainda passam ao largo dos resultados que se pretende alcançar. Certamente existe uma tendência de abrigar ainda as formas degradadoras das atividades desta natureza, mas começam a aparecer mudanças tímidas, sinalizando uma quebra deste paradigma de atribuir a exploração uma possibilidade real de recuperação do ambiente degradado.

Essa consciência desperta na sociedade uma tentativa de se unir na proteção ambiental, provocando silencioso processo de mudança que envolve situações políticas. Cabe ressaltar que o Plano de Recuperação de área Degradada - PRAD deve ter peso diferenciado na aprovação do Licenciamento. É ele que regulará as atividades, protegendo a área da degradação. O PRAD é, com certeza, uma ferramenta estratégica para avançar na conservação ambiental diante das atividades de exploração.

As características adaptativas e biológicas das espécies utilizadas no PRAD, são fatores fundamentais a serem considerados. A revegetação deve ser feita com espécies adequadas às condições existentes no local, principalmente luz, água e solo, sendo recomendável à utilização de espécies nativas de ocorrência nas formações vegetais o mais próximo possível do local.

Outro ponto importante no sucesso do PRAD é a realização da manutenção, avaliação e monitoramento da área objeto em estudo.

\section{REFERÊNCIAS BIBLIOGRÁFICAS}

ALMEIDA, R. O. P. O e SÁNCHEZ, L, E. Recomposição de Matas Ciliares. IF Série Registrus, São Paulo, n.4, p.1-14,1990.

ALVARENGA, A. P. 2004. Avaliação inicial da recuperação de mata ciliar em nascentes. Dissertação de Mestrado. Universidade Federal de Lavras. Minas Gerais. $175 \mathrm{p}$.

BRUM, I. A. S., CARVALHO, I. G., OLIVEIRA Jr., J. B. e CASSA, J. C. Mineração e meio ambiente - Uma avaliação do Estado da Bahia/Brasil. TecBahia - Revista Baiana de Tecnologia, Camaçari, V II, n. 03, p.216-226, Set./Dez.1996. 
CARPANEZZI, A. A. Talhões pioneiros para a recuperação de ecossistemas florestais degradados. In: SEMINÁRIOS ASPECTOS ECOLÓGICOSbDE MATAS MESÓFILAS SEMIDECÍDUAS,1991, Rio Claro. Texto de apoio... Rio Claro: UNESP, 1991. p. 94-104. (versão 1).

CARVALHO, A. R. Fitossociologia e modelo de distribuição de espécies em floresta ombrófila densa degradada por mineração, Joinville/ SC. Revista Saúde e Ambiente, v.4, p.42-51, 2003.

CRESTANA, M. S. M.; TOLEDO FILHO, D. V. de; CAMPOS, J. B. Florestas sistemas de recuperação com essências nativas. Campinas: Coordenadoria de Assistência Técnica Integral - CATI, 1993. 60 p.

DURIGAN, G.; NOGUEIRA, J. C. B. Recomposição de matas ciliares. IF Série Registros, São Paulo, n. 4, p. 1-14, 1990.

FELFILI, J. M.; VENTUROLI, F. Tópicos em análise de vegetação. Comunicações Técnicas Florestais, v.2, n.2, p.1-25, 2000.

GENTRY, A. H. Patterns of neotropical plant species diversity. Evolutionary Biology, v.15, p.1-84,1982.

INSTITUTO SOCIOAMBIENTAL. Números divulgados pelo governo apontam diminuição expressiva dos índices de desmatamento. 29 ago. 2005. Disponível em <http://www.isa.org.br.> Acesso em: 25 set. 2007.

LEITE, P. \& KLEIN, R.M. 1990. Vegetação. In: IBGE. Geografia do Brasil: região Sul. v. 2. Rio de Janeiro. Instituto Brasileiro de Geografia e Estatística. 113-150.

MACEDO, A. C de. 1993. Revegetação matas ciliares e de proteção ambiental. Governo do Estado de São Paulo. Secretaria Estadual do Meio Ambiente. Fundação Florestal. São Paulo, SP.

NOGUEIRA, P. Reflorestamento heterogêneo com essências indígenas. São Paulo: Instituto Florestal, 1977. 71 p. (Bol. Técn. IF, 24).

REIS, A. \& AMARAL, L da G. 1997. Projeto: Formação continuada para professores do $2^{\circ}$ grau na área de biologia. Centro de Ciências Biológicas. Departamento de Botânica. UFSC. Florianópolis, SC. 65p. 